\section{A novel traction method using an endoclip attached to a nylon string during colonic endoscopic submucosal dissection}

Colorectal endoscopic submucosal dissection (ESD) is considered to be a difficult procedure that has a high risk of adverse events [1]. Endoscopic procedures should be performed under direct visualization, but it is often difficult to maintain appropriate visualization during submucosal dissection. A traction method using an endoclip attached to a string was developed in order to maintain good visualization of the submucosal layer during esophageal and gastric ESD [2,3]. However, this method was not applicable to colonic ESD because the colonoscope required reinsertion in order to mount the

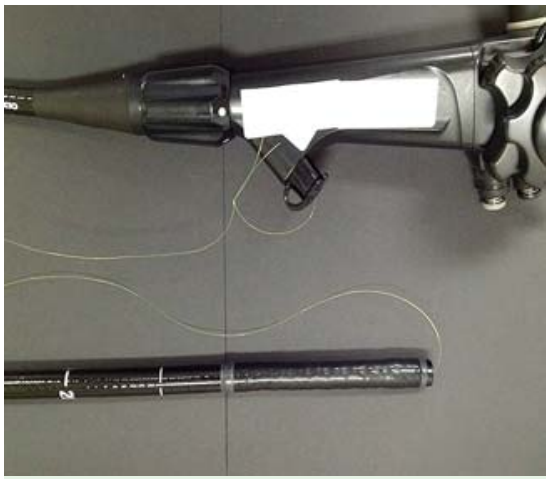

Fig. 1 The nylon string was tied outside of the colonoscope.
endoclip.We designed a novel traction method that did not require reinsertion of the colonoscope.

A total of 15 patients underwent colonic ESD using this novel traction method at our endoscopy unit. First, a nylon string was inserted into the accessory channel of a colonoscope by grasping the end of the string with hemostatic forceps (FD410LR; Olympus, Tokyo, Japan), and pulling the string back up through the channel of the colonoscope. Next, the ends of the string were tied together outside of the colonoscope ( $\nabla$ Fig. 1). The colonoscope was then inserted ( $\bullet$ Fig. 2 ), and a mucosal

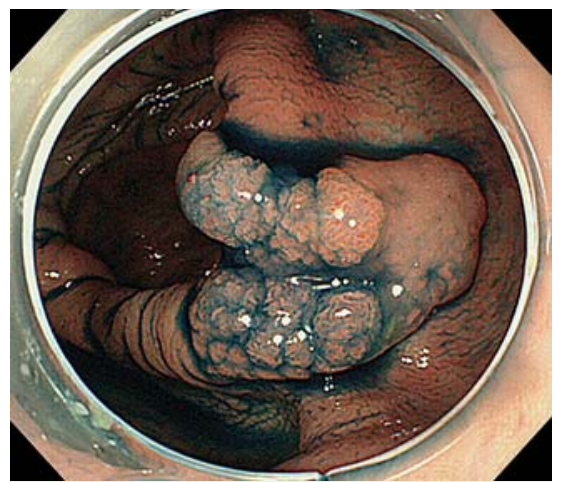

Fig. 2 Colonoscopy showed a large $(35 \mathrm{~mm})$ elevated lesion in the ascending colon. incision was performed. The nylon string was then cut externally at the hand control end of the colonoscope, and the accessory channel end of the string was tied to the teeth of an endoclip (HX-610-090; Olympus) ( Fig. 3, Video 1 ), which was attached to an applicator. Care was taken to not fully open the endoclip. The clip was then retracted into the applicator, and the applicator was inserted into the accessory channel. The endoclip grasped the anal side of the specimen ( $\bullet$ Fig. 4 a, b), and the nylon string was pulled gently ( $\bullet$ Fig. 4c - Video 1). Finally, the submucosal layer was dissected easily under direct visualization. All tumors were resected en bloc without adverse events.

This traction method using an endoclip and nylon string, without the need for colonoscope reinsertion, is a new and feasible colonic ESD technique. This method may improve the ease and safety of colonic ESD.

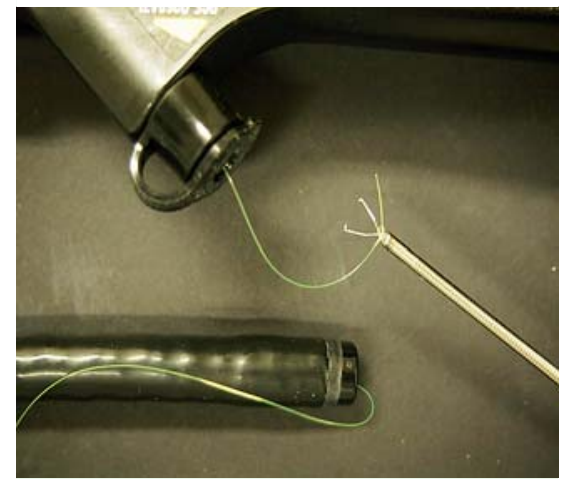

Fig. 3 With the colonoscope still inside the patient, the knot in the nylon string was cut using scissors. The accessory channel end of the string was tied to the teeth of an endoclip. The photo shows the colonoscope outside of the patient, to illustrate the string and clip arrangement.

\section{Video 1}

Novel traction method to improve visibility during endoscopic submucosal dissection. A nylon string is looped through the accessory channel of the colonoscope, and passed down along the outside of the colonoscope, the two ends being tied together near the hand control. In practice, the colonoscope was then inserted into the patient, and remained in situ for the rest of the procedure. Following mucosal incision, the knot in the nylon string was cut using scissors, and the string was tied to the teeth of an endoclip, which was then retracted into the endoclip applicator and inserted into the accessory channel of the colonoscope. (The video shows the colonoscope outside of the patient in order to illustrate the string and clip arrangement.) The endoclip with the nylon string grasped the anal side of the specimen and the string was pulled gently, resulting in good visibility of the submucosal layer. 

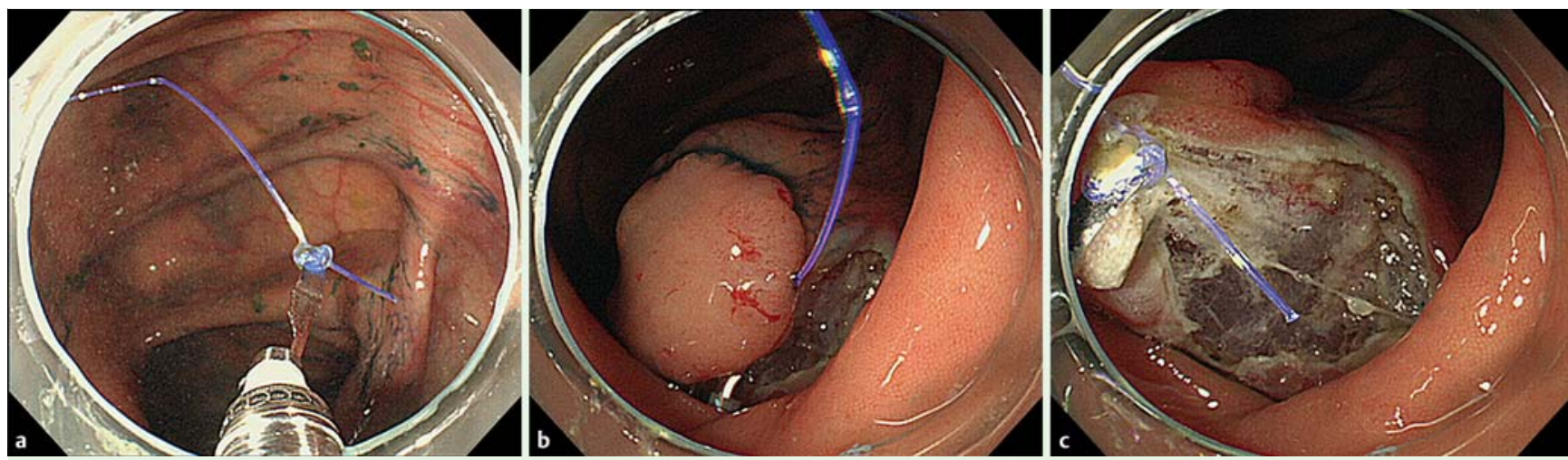

Fig. 4 Application and use of the endoclip during endoscopic submucosal dissection. a The endoclip with the nylon string was fully opened. b The endoclip grasped the anal side of the specimen. $\mathbf{c}$ The nylon string was gently pulled, the submucosal layer was lifted, and good visibility was obtained.

Endoscopy_UCTN_Code_TTT_1AQ_2AD

\section{Competing interests: None}

\section{Yasushi Yamasaki, Yoji Takeuchi, Noboru Hanaoka, Koji Higashino, Noriya Uedo, Ryu Ishihara, Hiroyasu lishi}

Department of Gastrointestinal Oncology, Osaka Medical Center for Cancer and Cardiovascular Diseases, Osaka, Japan

\section{References}

1 Takeuchi $Y$, Iishi H, Tanaka S et al. Factors associated with technical difficulties and adverse events of colorectal endoscopic submucosal dissection: retrospective exploratory factor analysis of a multicenter prospective cohort. Int J Colorectal Dis 2014; 29: $1275-1284$

2 Oyama T. Counter traction makes endoscopic submucosal dissection easier. Clin Endosc 2012; 45: 375-378

3 Ota M, Nakamura T, Hayashi K et al. Usefulness of clip traction in the early phase of esophageal endoscopic submucosal dissection. Dig Endosc 2012; 24: 315-318
Bibliography

DOI http://dx.doi.org/

10.1055/s-0034-1391868

Endoscopy 2015; 47: E238-E239

(c) Georg Thieme Verlag KG

Stuttgart · New York

ISSN 0013-726X

\section{Corresponding author}

\section{Yoji Takeuchi, MD}

Department of Gastrointestinal Oncology Osaka Medical Center for Cancer and Cardiovascular Diseases

1-3-3, Nakamichi, Higashinari-ku Osaka 537-8511

Japan

Fax: +81-6-69814067

takeuti-yo@mc.pref.osaka.jp 